\title{
STRESSORS AND THE LEVELS OF STRESS AMONG THE UNDERGRADUATE MEDICAL, DENTAL AND NURSING STUDENTS OF A MEDICAL COLLEGE IN KATHMANDU
}

\author{
Manandhar SA, Pramanik T
}

Department of Physiology, Nepal Medical College Teaching Hospital, Attarkhel, Gokarneshwor-8, Kathmandu, Nepal

\begin{abstract}
Educational environment in medical schools is highly demanding and stressful due to various factors. The study was aimed to explore level of stress, stressors and the coping strategies among the undergraduate medical, dental and nursing students of a medical college in Kathmandu. A cross- sectional observational study was conducted among 174 consenting (95 medical, 51 dental and 28 nursing) first year undergraduate students with predesigned, pretested, semi-structured questionnaire which included socio-demographic details, Kessler psychological distress scale and Medical student stress questionnaire. Average age of students was $19.54 \pm 1.28$ years. Results revealed that $66.66 \%$ of students were under stress with $25.86 \%$ having mild, $18.96 \%$ having moderate and $21.83 \%$ having severe levels of stress. Highest prevalence of stress was noted among nursing students (75.00\%) with $32.14 \%$ under severe stress. Among 116 males and 58 females, males were more stressed (75.00\%) than females (50.00\%). Most of the students enjoyed music and chatted with their close ones to cope with stress. Academic related stressor was found to be the major stressor $(2.65 \pm 0.69)$ with statistically significant association $(p<0.01)$ with the stress levels among the students. Informing students about the "must know" and "good to know" areas of the topics of every subject may be helpful to decrease the academic related stress. Regular practice of meditation, sports and cultural activities may help to reduce stress.
\end{abstract}

\section{KEYWORDS}

Kessler psychological distress scale, medical student stress questionnaire, stress, stressors

\section{CORRESPONDING AUTHOR}

Dr. Seerina Adhikari (Manandhar),

Department of Physiology,

Nepal Medical College Teaching Hospital,

Attarkhel, Gokarneshwor-8, Kathmandu, Nepal,

Email: seerina1978@gmail.com 


\section{INTRODUCTION}

Stress is defined as the body's nonspecific response or reaction to demands made on it, or to disturbing events in the environment. ${ }^{1,2}$ It is not just a stimulus or a response but it is a process by which we perceive and cope with environmental threats and challenges. ${ }^{3}$ Personal and environmental events that cause stress are known as stressors. ${ }^{4,5}$ Stress may be physical or emotional. Linn and Zeppa stated that some stress in medical training is needed for learning. ${ }^{6}$ However, the same stressors may be perceived differently by individuals, depending upon their cultural background, personal traits, experience and coping skills. ${ }^{7}$ Undergraduate medical students especially those in first year, are exposed to tremendous stress as they face a sudden transition from the phase of rote learning to self-directed learning in college days. Inability to cope with the stress may affect their physical and mental well-being. ${ }^{8}$ Reports support that among the medical students, the incidence of psychological distress and morbidity ranging from mental stress, interpersonal problems, suicidal tendency and psychiatric problem are more than that in the general population. ${ }^{9}$ Dental and nursing students face similar challenges. Undergraduate students of dental surgery course are expected to acquire academic and clinical competencies as well as interpersonal skills. ${ }^{10}$ During nursing education and training, undergraduate nursing students are also frequently exposed to various stressors which may directly or indirectly impede their learning and performance. ${ }^{11}$ Hence, this study aimed to identify the level of stress and stressors.

\section{MATERIALS AND METHODS}

A cross-sectional observational study was conducted among first year MBBS, BDS and BSc nursing students of Nepal Medical College $(n=174)$ from June 2018 - July 2018, after obtaining institutional ethical clearance and informed consent from the students. The pretested, predesigned, semi-structured questionnaire consisted of 3 parts:

Part 1: Socio-demographic characteristics like age, sex, socio-economic status etc.

Part 2: Kessler psychological distress scale (K10) Psychological Distress Scale. It consists of 10 questions and the responses were marked on Likert scale. "0" denoted presence of no stress. Whereas " 1 ", " 2 " and " 3 " that represented mild, moderate and severe stress respectively, were collectively labeled as "presence of stress." 12

Part 3: Medical Student Stress Questionnaire (MSSQ) that consisted of 40 items which are marked based on Likert scale from 0 to 4 (no stress to severe stress respectively), each item which may be a potential source of stress. These stress factors are further grouped into 6 domains of stressors namely, Academic related stressors (ARS), Intra- and interpersonal related stressors (IRS), Teaching and learning related stressors (TLRS), Social related

stressors (SRS), Drive and desire related stressors (DRS) and Group activity related stressors (GARS). Mean score of 0.00 to 1.00 - indicate mild stress, 1.01 to 2.00- moderate stress, 2.10 to 3.00 - high stress and 3.01 to 4.00 - severe stress. Mild stress indicates that it causes very little stress, moderate stress indicates presence of stress, but in a manageable range, high stress represents emotional disturbance and compromises daily activities mildly and severe stress results extreme emotional disturbances severely compromising the daily activities. ${ }^{7}$

The participants were allowed to fill up the aforesaid questionnaire within 20 minutes without consulting others. The collected data was compiled in Microsoft Excel 2007 worksheet. Statistical analysis was carried out using SPSS version 16.0 software. Logistic regression analysis was used to verify the association between the level of stress and stressors.

\section{RESULTS}

In the present study, 116 (66.66\%) were males and $58(33.33 \%)$ were females. The minimum age of the participants was 17 years and maximum age was 29 years. The mean age of the participants was 19.54 \pm 1.28 years.

As depicted in Table-1, most of students resided in the hostel (71.26\%). Majority $(77.58 \%)$ of them were from nuclear family and belonged to upper middle socio-economic class (50.57\%), at least one parent was educated (95.40\%), slept for 6 to 8 hours (66.66\%) and

Table-1: Distribution of participants according to socio-demographic variables

\begin{tabular}{lccc}
$\begin{array}{l}\text { Socio- } \\
\text { demographic } \\
\text { variables }\end{array}$ & & Frequency & $\%$ \\
Residence & Hostel & 124 & 71.26 \\
& Non hostel & 50 & 28.73 \\
Family size & $\leq 5$ & 135 & 77.58 \\
$\begin{array}{l}\text { At least } \\
\text { one parent } \\
\text { educated }\end{array}$ & Yes & 166 & 22.41 \\
$\begin{array}{l}\text { Socio- } \\
\text { economic } \\
\text { condition } \\
\text { (Kuppuswami }\end{array}$ & Class II & 88.40 \\
scale) & Class III- V & 19 & 10.91 \\
$\begin{array}{l}\text { History of } \\
\text { chronic }\end{array}$ & Yes & 74 & 42.52 \\
illness & No & 100 & 57.47 \\
Sleep hours & 6-8 hours & 116 & 66.59 \\
& $>8$ hours & 12 & 6.89 \\
\hline
\end{tabular}


Table-2: Personal history of the students

$\begin{array}{lccc}\text { Variables } & & \text { Frequency } & \% \\ \text { Bowel habit } & \text { Regular } & 143 & 82.18 \\ \text { Fruits consumption } & \text { Irregular } & 31 & 17.81 \\ & >\text { 3times/ week } & 71 & 40.80 \\ \text { Junk food consumption } & <\text { 3times/week } & 103 & 59.19 \\ \text { Skipping of meal } & >\text { 3times/ week } & 119 & 68.39 \\ & <3 \text { times/ week } & 55 & 31.60 \\ \text { Fasting } & \text { Yes } & 100 & 57.47 \\ & \text { No } & 74 & 42.52 \\ & \text { Yes } & 25 & 14.36 \\ & \text { No } & 149 & 85.63\end{array}$

\section{Table-3: Gender-wise prevalence of stress among the students using K10}

\begin{tabular}{lcccccc|} 
Gender & $\begin{array}{c}\text { No stress } \\
(\mathbf{n})\end{array}$ & $\begin{array}{c}\text { Mild stress } \\
(\mathbf{n})\end{array}$ & $\begin{array}{c}\text { Moderate } \\
\text { stress (n) }\end{array}$ & $\begin{array}{c}\text { Severe } \\
\text { stress (n) }\end{array}$ & $\begin{array}{c}\text { Percentage } \\
\text { of severe } \\
\text { stress (\%) }\end{array}$ & $\begin{array}{c}\text { Prevalence } \\
\text { of stress (\%) }\end{array}$ \\
Male (n=116) & 29 & 36 & 21 & 30 & 25.86 & 75.00 \\
Female (n=58) & 29 & 9 & 12 & 8 & 13.79 & 50.00
\end{tabular}

$\mathrm{n}=$ Number of participants

had no history of chronic illness in the family (57.47\%).

Table-2 showed majority of them (82.18\%) had regular bowel habits, but consumed fruits less than 3 times a week (59.19\%). More than half of them consumed junk food more than 3 times in a week (68.39\%), skipped meals (57.47\%) and only few did fasting (14.36\%). Overall stress $(75.00 \%)$ as well as the level of severe stress $(25.86 \%)$ was higher in males than in females as shown by Table-3. It is evident from Table- 4 that prevalence of stress among the students of different faculties was $66.66 \%$. Highest percentage of stress was found in nursing students (75.00\%), followed by dental students (68.62\%) and medical students (63.15\%). Academic related stressor followed by group activities related, teaching and learning related and social related stressors were the major stressors in descending order according to Table-5.

\begin{tabular}{|lccccccccc|}
\multicolumn{8}{c|}{ Table-4: Stress levels among the students of different faculties using K10 } \\
Faculty & No (n) & $\mathbf{( \% )}$ & Mild (n) & $\mathbf{( \% )}$ & $\begin{array}{c}\text { Moderate } \\
\text { (n) }\end{array}$ & $\mathbf{( \% )}$ & $\begin{array}{c}\text { Severe } \\
\text { (n) }\end{array}$ & (\%) & $\begin{array}{c}\text { Prevalence } \\
\text { of stress (\%) }\end{array}$ \\
MBBS (n=95) & 35 & 36.84 & 24 & 25.26 & 17 & 17.89 & 19 & 20.00 & 63.15 \\
BDS (n=51) & 16 & 31.37 & 11 & 21.56 & 14 & 27.45 & 10 & 19.60 & 68.62 \\
Nursing (n=28) & 7 & 25.00 & 10 & 35.71 & 2 & 7.14 & 9 & 32.14 & 75.00 \\
n=174 & 58 & 33.33 & 45 & 25.86 & 33 & 18.96 & 38 & 21.83 & 66.66 \\
\hline
\end{tabular}

$\mathrm{n}=$ Number of participants

\begin{tabular}{|lcccccccc|}
\multicolumn{7}{c}{ Table-5: Levels of stress measured among the students by using MSSQ } \\
Domains & $\begin{array}{c}\text { Mild } \\
\text { stress (n) }\end{array}$ & $\begin{array}{c}\text { Moderate } \\
\text { stress (n) }\end{array}$ & $\begin{array}{c}\text { High stress } \\
\text { (n) }\end{array}$ & $\begin{array}{c}\text { Severe } \\
\text { stress (n) }\end{array}$ & Q1 & Q3 & Median & Mean score \\
ARS & 9 & 55 & 97 & 13 & 2 & 3 & 3 & $2.65 \pm 0.69$ \\
IRS & 45 & 71 & 54 & 4 & 1 & 3 & 2 & $2.09 \pm 0.80$ \\
TLRS & 36 & 75 & 61 & 2 & 2 & 3 & 2 & $2.16 \pm 0.76$ \\
SRS & 26 & 100 & 47 & 1 & 2 & 3 & 2 & $2.13 \pm 0.65$ \\
DRS & 77 & 69 & 24 & 4 & 1 & 2 & 2 & $1.74 \pm 0.78$ \\
GARS & 30 & 84 & 52 & 8 & 2 & 3 & 2 & $2.21 \pm 0.78$ \\
\hline
\end{tabular}

$\mathrm{n}=$ Number of participants, ARS- Academic related stressor; IRS- Interpersonal/ intrapersonal related stressor; TLRS- Teaching and learning related stressor; SRS- Social related stressor; DRS- Drive and desire related stressor; GARS- Group activities related stressor. 
Table-6: Logistic regression for association

between level of stress (K10) and stressors (MSSQ) among participants

\begin{tabular}{|c|c|c|c|c|}
\hline \multirow{2}{*}{ Stress Factors } & \multirow{2}{*}{ OR } & \multicolumn{2}{|c|}{$95 \%$ CI for OR } & \multirow{2}{*}{$\underset{\text { value }}{\mathbf{P}}$} \\
\hline & & Lower & Upper & \\
\hline & 2.913 & & & \\
\hline IRS (I & . & & & \\
\hline TLRS (M & 1.515 & & & 0.2 \\
\hline SRS ( & 0.824 & & & 0.598 \\
\hline DRS (M & 1.605 & & & \\
\hline GARS (MSSQ6) & 1.074 & 0.601 & 1.917 & 0.810 \\
\hline
\end{tabular}

As depicted in Table-6, the association between stress levels in students and academic related stressor is statistically significant with $\mathrm{p}<0.01$.

\section{DISCUSSION}

Stress is indeed a global problem today. Previous studies revealed that undergraduate medical, dental and nursing students face highly demanding and stressful educational environment affecting their physical and mental health. ${ }^{8-11}$ The present study also noted $66.66 \%$ of the students under stress with $25.86 \%$ having mild stress, $18.96 \%$ having moderate stress and $21.83 \%$ having severe levels of stress. The findings corroborate the previous study by Singh et $a l . .^{13}$ Present study also revealed that among the MBBS students, $63.15 \%$ had stress. Different levels of stress ranging from $29.60 \%$ to $78.19 \%$ were found in previous studies done among the MBBS students of Malaysia, Basrah, Thailand and India. ${ }^{14-17}$ Prevalence of stress was found to be $100 \%$ among the undergraduate dental students in a study conducted in eastern Nepal. ${ }^{18}$ Nevertheless, present study revealed lower prevalence of stress (68.62\%) among BDS students. However, Basudan et al reported that only $54.70 \%$ Saudi Arabian BDS students were under stress. ${ }^{19}$ Our study revealed stress among $75.00 \%$ of BSc nursing students, with $32.14 \%$ under severe stress. Whereas, studies by Kumar et al and Singh et al noted the same in $33.00 \%$ and $23.00 \%$ of BSc nursing students respectively. ${ }^{20,21}$ Nursing students were found to have highest percentage of severe stress levels than the dental and medical students in the present study. To the best of our knowledge, no literature has compared the stress levels among the students of three faculties. Hence, the vast syllabus that the undergraduate nursing students have to cover during their initial years along with the clinical posting might be the cause of this extreme stress on them. ${ }^{22}$ Higher percentage of males were found to be under greater level of stress in comparison to the female counterparts which differs from the findings of previous studies done by Hamza et al, Eva et al and Atalla et al, that reported the female students in medical colleges were under higher stress level than the male ones. ${ }^{23-25}$ It may be due to the social structure in those Muslim countries which differs from us.
To find out the solution to a problem, one must find the cause. Keeping this in mind, our study tried to excavate the stressors among the participants. In our study, academic related stressors followed by, group activities related, teaching and learning and social related stressors were the major stressors faced by the students. The findings are similar to the study done by Patil et al. ${ }^{26}$ The study by Mehta et al indicated academic related stressors, intrapersonal and interpersonal related and group activities related stressors as the major stressors. ${ }^{27}$ Similarly, Panchu et al also noticed that academically related stressors, followed by inter and intra-personal related and group activity related stressors were the most common stressors among the medical students. ${ }^{28}$ It seems that results of most of the studies found academic related stressor as the topmost stressor perceived by the students in medical colleges. Academic related stress occurs due to huge syllabus to be studied within limited time frame and to take examinations in a competitive environment. ${ }^{7}$

Students of higher education in the field of medical, dental and nursing education generally face highly stressful academic environment. ${ }^{13,14}$ Some of the factors that create this includes, diversity of subjects, huge syllabus and constraint of time. In this regards, the study opines that medical colleges should have a holistic approach and bring up ideas to minimize the impact of the stressors. The college authorities should provide proper counseling services to students under stress, inform them about the "must know" and "good to know" areas of each topic of every subject clearly, run regular sessions of meditation, yoga, sports and cultural activities to reduce stress and improve strength to cope with the situation.

Present study revealed higher prevalence of moderate and severe stress among undergraduate nursing students in comparison to MBBS and BDS students. To further explore the cause, a larger and in-depth study is needed.

\section{ACKNOWLEDGEMENT}

Authors are thankful to the students for their participation in this work.

\section{REFERENCES}

1. Rosenham DL, Seligman ME. Abnormal psychology. $2^{\text {nd }}$ ed. New York: Norton 1989.

2. Selye H. Stress without distress. New York: Harper and Row 1974.

3. Myers DG. Stress and Health. In Exploring Psychology. (6 ${ }^{\text {th }}$ ed). New York: Worth Publishers 2005.

4. Lazarus RS. Theory-based stress measurement. Psychol Inquiry 1990; 1: 3-13.

5. Linn BS, Zeppa R. Stress in junior medical students: 
relationship to personality and performance. J Med Educ 1984; 59: 7-12.

6. Lazarus RS, Folkman S. Stress, appraisal and coping. New York: Springer 1984.

7. Yusoff MSB. A multicenter study on validity of the medical student stressor questionnaire (MSSQ). Int Med J 2011; 18: 14-18.

8. Sarkar D, Saha J. Assessment of stress among first year medical students of Chattisgarh. IOSR J Dent Med Sci 2015; 14: 37-40.

9. Supe AN. A study of stress in medical students at Seth G. S. Medical College. J Post Grad Med 1998; 44: 1-6.

10. Polychronopoulou A, Divaris K. Dental students' perceived sources of stress: a multi-country study. J Dent Educ 2009; 73: 631-9.

11. Labrague LJ. Stress, stressors and stress response of student nurses in a government nursing school. Health Sci J 2013; 7: 424-34.

12. Kessler RC, Andrews GC, Colpe LJ et al. Short screening scales to monitor population prevalence and trends in non-specific psychological distress. Psychol Med 2002; 32: 959-76.

13. Singh S, Katwal B, Pant PP. Assessment of stress among medical undergraduate students of Nepal Medical College and Teaching Hospital (NMCTH). Intl J Sci Healthcare Res 2017; 2: 15-18.

14. Muhamad SBY, Ahmad FAR, Yaacob MJ. Prevalence and sources of stress among medical students in University Sains Malaysia. Malays J Med Sci 2010; 17: 30-7.

15. Sharif S, Al-Kamil E, Attiya M. Stress and coping strategies among medical students in Basrah. Med J Basrah Uni 2007; 25: 28-32.

16. Saipanish R. Stress among medical students in a Thai medical school. Med Teach 2003; 25: 502-06.

17. Arepalli S, Guthi VR, Pardhu B et al. Study of stress among the first year medical student of Kurnool Medical College, Kurnool. Int J Med Sci Public Health 2016; 5: 852-55.
18. Paudel S, Subedi N, Shrestha A. Stress and it's relief among undergraduate dental students in a tertiary health care center in eastern Nepal. Dentistry 2013; 3: 157.

19. Basudan S, Binanzan N, Alhassan A. Depression, anxiety and stress in dental students. Int'l J Med Educ 2017; 8: 179-86.

20. Kumar R, Nancy. Stress and coping strategies among nursing students. Nursing Midwifery Res J 2011; 7: 141-51.

21. Singh C, Sharma S, Sharma RK. Level of stress and coping strategies used by nursing interns. Nursing Midwifery Res J 2011; 7: 152-60.

22. Bachelor of Science in Nursing. Kathmandu University School of Medical Sciences (Nursing Program). Curriculum revised 2016.

23. Hamza MA, Abdulaziz AA, Ebrahim SM et al. Stress and its effects on medical students: A crosssectional study at a College of Medicine in Saudi Arabia.J Health Popul Nutr 2011; 29: 516-52.

24. Eva EO, Islam MZ, Mosaddeek ASM et al. Prevalence of stress among medical students: a comparative study between public and private medical schools in Bangladesh. BMC Res Notes 2015; 8: 327.

25. Atalla A, Altuwairqi YA. Prevalence of stress among junior medical students, Taif University. J Com Med Health Educ 2017; 7: 537.

26. Patil SP, Sadhanala S, Srivastav MU et al. Study of stressors among undergraduate medical students of a teaching medical institution. Int'l J Community Med Public Health 2017; 4: 3151-54.

27. Mehta P, Thekdi K, Rokad M et al. Exploratory study to access anxiety, depression and stress among medical students, freshly starting their medical education in a medical college. Sch J App Med Sci 2013; 1: 819-22.

28. Panchu P, Bahuleyan Biju, Vijayan V. An analysis of the factors leading to stress in Indian medical students. Int J Clin Exp Physiol 2017; 4: 48-50. 